\title{
Association of the polymorphism in NUCB2 gene and the risk of type 2 diabetes
}

\author{
Chunyu Wang ${ }^{1 \dagger}$, Yulun Wang ${ }^{2 \dagger}$ and Wenchao $\mathrm{Hu}^{3 *}$
}

\begin{abstract}
Background: Nesfatin-1, originating from its precursor protein called nucleobindin 2 (NUCB2), plays an important role in glucose metabolism and diabetes. The aim of this study is to examine the association of the c.1012C>G (rs757081) polymorphism of NUCB2 gene with the presence of T2DM.

Methods: This study was performed in a population of 396 patients with T2DM and 196 healthy subjects. The c.1012C>G polymorphism of NUCB2 gene was determined using polymerase chain reaction and sequencing method.

Results: T2DM patients showed lower CG and GG genotype, as well as $G$ allele frequencies compared with healthy subjects. Logistic regression analysis showed that c.1012C $>G$ polymorphism was associated with a decreased risk of developing T2DM. In addition, GG genotype of NUCB2 was significantly correlated with lower levels of body mass index and fasting plasma glucose in patients with T2DM.
\end{abstract}

Conclusions: The c.1012C>G polymorphism of NUCB2 is associated with the decreased risk of developing T2DM in Chinese Han population.

Keywords: Polymorphism, Nucleobindin 2, Nesfatin-1, Type 2 diabetes

\section{Background}

Type 2 diabetes mellitus (T2DM) is a chronic metabolic disease characterized by hyperglycemia. In the last few decades, the prevalence of T2DM is increasing rapidly in the world [1]. T2DM causes significant morbidity, disability, and early mortality, and imposes a huge economic burden on the individual, national healthcare, and economy [2]. Both genetic and environmental factors contribute to the incidence of T2DM. T2DM is considered to be a complex multi-gene disorder. A number of genes and their polymorphisms have been shown to contribute to the pathogenesis of this disease [3].

Nucleobindin 2 (NUCB2), containing 396 amino acid residues, is a precursor of nesfatin-1 (residues 1-82), nesfatin-2 (residues 85-163), and nesfatin-3 (residues 166396) [3]. Nesfatin-1 is a protein comprising 82 amino

\footnotetext{
*Correspondence: tjmuhwc@126.com

${ }^{+}$Chunyu Wang and Yulun Wang contributed equally to this work

${ }^{3}$ Department of Endocrinology, Qilu Hospital of Shandong University (Qingdao), 758 Hefei Road, Shibei District, Qingdao 266035, Shandong, China

Full list of author information is available at the end of the article
}

acids and is highly conserved in humans, rats, and mice [3]. Nesfatin-1 regulates the glucose and energy metabolism in multiple processes. Nesfatin-1 stimulates insulin secretion from pancreatic $\beta$-cells, improves insulin sensitivity, and contributes to energy storage [4]. Furthermore, plasma nesfatin-1 concentrations are significantly decreased in T2DM patients compared with healthy controls $[5,6]$. These findings suggest the possible role of nesfatin- 1 in the pathogenesis of T2DM.

A recent study performed in a population of 1049 obese Caucasian subjects indicated an association of three single nucleotide polymorphisms (SNPs) (rs1330, rs214101 and rs757081) in the NUCB2 gene with obesity [7]. Chen et al. then reported that one SNP of NUCB2 gene, c.1012C $>$ G (Q338E or rs757081) was correlated with childhood adiposity [8]. These data indicate that polymorphisms in the NUCB2 gene could play an important role in the protection against the development of obesity. Obesity is closely correlated with the risk of T2DM. Therefore, it is hypothesized that c. $1012 \mathrm{C}>\mathrm{G}$ polymorphism of NUCB2 may be associated with the risk of T2DM. 
The present study is performed to examine the association of c.1012C>G polymorphism of NUCB2 gene with the risk of T2DM in Chinese Han population.

\section{Methods Subjects}

This study consisted of 396 patients with T2DM. These patients were diagnosed with T2DM according to the criteria using a fasting plasma glucose (FPG) level $\geq 7.0 \mathrm{mmol} / \mathrm{L}$ or 2 -h postprandial plasma glucose $\left(\mathrm{P}_{2 \mathrm{~h}} \mathrm{PG}\right)$ level $\geq 11.1 \mathrm{mmol} / \mathrm{L}$. Patients who had a clinical history of T2DM and were receiving oral hypoglycemic or parental insulin medications were also eligible for this study. However, those with type 1 diabetes were excluded from this study. The control group consisted of 196 normal subjects who had no history of diabetes. None was receiving medication or dietary supplements. All T2DM patients and controls were Chinese Han population.

The study was approved by the Hospital ethics board and all patients provided written informed consent.

\section{Measurements}

Weight, height, systolic blood pressure (SBP), and diastolic blood pressure (DBP) were measured. Venous blood was collected after a minimum of $10 \mathrm{~h}$ of fasting. FPG, serum triglycerides (TG), total cholesterol (TC), highdensity lipoprotein cholesterol (HDL-C), and low-density lipoprotein cholesterol (LDL-C) were tested using an auto biochemistry instrument (Hitachi 7170, Tokyo, Japan). Body mass index (BMI) was calculated as weight in kilograms divided by height squared in meters $\left(\mathrm{kg} / \mathrm{m}^{2}\right)$.

\section{DNA genotyping}

Blood samples were collected from all subjects. Genomic DNA was extracted from peripheral blood using a DNA extraction kit (Qiagen, Valencia, CA). c.1012C $>\mathrm{G}$ polymorphism of NUCB2 gene was detected using polymerase chain reaction (PCR) and sequencing method. The primer sequences for genotyping the c. $1012 \mathrm{C}>\mathrm{G}$ polymorphism of NUCB2 gene were as follows: $5^{\prime}$-ATCCTAATGACTTTGACCCC- $3^{\prime}$ (forward) and 5'-TGAGGAGACATCTTGCACCAC- $3^{\prime}$ (reverse). The PCR was performed with $5 \mathrm{~min}$ of a initial denaturation at $95{ }^{\circ} \mathrm{C}$, followed by 35 cycles of $30 \mathrm{~s}$ at $95^{\circ} \mathrm{C}, 45 \mathrm{~s}$ at $60^{\circ} \mathrm{C}$ and $45 \mathrm{~s}$ at $72{ }^{\circ} \mathrm{C}$. A final extension of $72{ }^{\circ} \mathrm{C}$ for 7 min completed the reaction. PCR products were directly sequenced by Sangon Biotech Company (Shanghai, China).

\section{Statistical analyses}

Data are presented as mean \pm standard deviation (SD). A Chi square test was performed to assess Hardy-Weinberg equilibrium. The value differences between T2DM and control group were compared by Student $t$ test or Chi squared test. Logistic regression analysis was used to determine the risk factors of developing T2DM. The variables of different NUCB2 genotypes among T2DM patients were analyzed using the one-way ANOVA or Chi squared test. A $P$ value less than 0.05 was considered statistically significant.

\section{Results}

\section{Baseline clinical characteristics}

As shown in Table 1, T2DM patients showed higher SBP, DBP, FPG, TG, and LDL-C, as well as lower HDL-C than did control subjects.

\section{Association of c.1012C $>\mathrm{G}$ polymorphism with the presence of T2DM}

Genotypes of c.1012C>G polymorphism in T2DM patients and control subjects are shown in Table 2. The genotype frequencies of $\mathrm{c} .1012 \mathrm{C}>\mathrm{G}$ polymorphism among the controls were in agreement with HardyWeinberg equilibrium $(P=0.597)$. The frequency of CG and GG genotypes, as well as $G$ allele was significantly decreased in T2DM patients compared with those in healthy controls $(P=0.019$ and $P=0.004)$.

\section{The association of c.1012C $>$ G polymorphism with T2DM}

As shown in Table 3, logistic regression analysis showed that c. $1012 \mathrm{C}>\mathrm{G}$ polymorphism was associated with a decreased risk of developing T2DM (OR 0.707, 95\% CI 0.554-0.901; $P=0.005$ ). After adjusting for age, gender, and BMI, c. $1012 \mathrm{C}>\mathrm{G}$ polymorphism was associated with a decreased risk of developing T2DM (OR 0.704, 95\% CI $0.551-0.899 ; P=0.005)$. Then a significant association of c.1012C $>$ G polymorphism with T2DM risk was found after adjusting for age, gender, $\mathrm{BMI}$, and serum lipid (OR

Table 1 Comparison of clinical and laboratory parameters between T2DM patients and control subjects

\begin{tabular}{lllr}
\hline Characteristics & $\begin{array}{l}\text { T2DM group } \\
(\mathbf{n}=\mathbf{3 9 6})\end{array}$ & $\begin{array}{l}\text { Control group } \\
(\mathbf{n}=\mathbf{1 9 6})\end{array}$ & $\boldsymbol{P}$ \\
\hline Age (years) & $56.57 \pm 11.81$ & $56.06 \pm 8.96$ & 0.594 \\
Gender (M/F) & $210 / 186$ & $106 / 90$ & 0.809 \\
BMI $\left(\mathrm{kg} / \mathrm{m}^{2}\right)$ & $24.96 \pm 3.67$ & $24.59 \pm 2.91$ & 0.218 \\
SBP $(\mathrm{mmHg})$ & $139.18 \pm 22.47$ & $121.67 \pm 10.77$ & $<0.001$ \\
DBP $(\mathrm{mmHg})$ & $84.17 \pm 12.99$ & $77.79 \pm 7.38$ & $<0.001$ \\
FPG $(\mathrm{mmol} / \mathrm{L})$ & $7.73 \pm 1.71$ & $5.00 \pm 0.49$ & $<0.001$ \\
TG $(\mathrm{mmol} / \mathrm{L})$ & $1.87 \pm 1.40$ & $1.54 \pm 1.20$ & 0.004 \\
TC $(\mathrm{mmol} / \mathrm{L})$ & $5.20 \pm 1.14$ & $5.05 \pm 0.84$ & 0.107 \\
HDL $(\mathrm{mmol} / \mathrm{L})$ & $1.27 \pm 0.32$ & $1.45 \pm 0.25$ & $<0.001$ \\
LDL $(\mathrm{mmol} / \mathrm{L})$ & $3.39 \pm 0.96$ & $3.18 \pm 0.60$ & 0.006 \\
\hline
\end{tabular}

Italic values indicate significance of $P$ value $(P<0.05)$ 
Table 2 Genotype and allele frequencies of the c.1012C $>$ G polymorphism of NUCB2 gene in T2DM subjects and control subjects

\begin{tabular}{lcccccc}
\hline Genotype & \multicolumn{2}{l}{$\begin{array}{l}\text { T2DM group } \\
(\mathbf{n = 3 9 6 )}\end{array}$} & & \multicolumn{2}{l}{$\begin{array}{l}\text { Control group } \\
(\mathbf{n}=\mathbf{1 9 6})\end{array}$} & P value \\
\cline { 2 - 3 } & $\mathbf{n}$ & $\%$ & & $\mathbf{n}$ & $\%$ & \\
\hline CC & 169 & 42.7 & & 63 & 32.1 & 0.019 \\
CG & 173 & 43.7 & & 93 & 47.4 & \\
GG & 54 & 13.6 & & 40 & 20.4 & \\
C & 511 & 64.1 & & 219 & 54.5 & 0.004 \\
G & 281 & 35.9 & & 173 & 45.5 & \\
\hline
\end{tabular}

Italic values indicate significance of $P$ value $(P<0.05)$

0.768, 95\% CI 0.589-0.989; $P=0.042$ ). However, when adjusted for additional blood pressure, c. $1012 \mathrm{C}>\mathrm{G}$ polymorphism was not associated with the risk of developing T2DM.

\section{T2DM patients with different genotypes}

The characteristics of different genotypes of c.1012C $>\mathrm{G}$ polymorphism in T2DM patients are presented in Table 4. GG genotype was significantly associated with decreased levels of BMI and FPG in T2DM patients. No significant differences in the other characteristics were observed between different genotypes.

\section{Discussion}

Nesfatin-1/NUCB2 is ubiquitously expressed in peripheral tissues including white adipose tissue. Furthermore, nesfatin-1/NUCB2 is selectively expressed in human and rodent beta cells but absent in alpha, delta, and PP cells [9]. Nesfatin-1/NUCB2 plays a key role in the regulation of glucose metabolism. Nesfatin-1 stimulated glucose-induced insulin secretion from mouse islets and MIN6 cells in a dose-dependent manner [10]. In addition, MIN6 cells showed a four-fold increase of nesfatin-1 release when following the incubation in high glucose compared to low glucose [10]. Riva et al. reported that nesfatin-1 enhanced glucagon secretion but had no effect on insulin secretion from mouse islets or INS-1 cells [9]. On the other hand, nesfatin-1 caused a small increase in insulin secretion and reduced glucose during intravenous glucose tolerance test in mice [9]. And human islet NUCB2 mRNA was up-regulated after cultured in glucolipotoxic conditions [9]. Another study demonstrated that hypothalamic nesfatin-1 infusion could contribute to increased peripheral and hepatic insulin sensitivity by decreasing gluconeogenesis and promoting peripheral glucose uptake in vivo [11]. In addition, inhibition of central nesfatin-1/NUCB2 activity markedly increased food intake and hepatic glucose flux, impaired hepatic insulin sensitivity, and decreased glucose uptake in peripheral tissue in rats [12]. Our study indicated that the GG genotype of c. $1012 \mathrm{C}>\mathrm{G}$ polymorphism was negatively correlated with lower FPG. These results assume an involvement of nesfatin-1 in the development of T2DM.

NUCB2 expression or nesfatin-1 levels were changed during diabetic condition. Both NUCB2 mRNA expression and nesfatin-1 immunoreactivity were found to be decreased in the pancreatic islets of mice with type 1 diabetes, while increased in the islets of diet-induced obese mice with T2DM [10]. Human islet NUCB2 mRNA was reduced in T2DM subjects compared those in the controls [9]. NUCB2 protein expression level was

Table 3 Logistic regression analysis for determining the risk factor of developing T2DM

\begin{tabular}{|c|c|c|c|c|c|c|}
\hline \multirow[t]{2}{*}{ Characteristics } & \multicolumn{2}{|l|}{ Model 1} & \multicolumn{2}{|l|}{ Model 2} & \multicolumn{2}{|l|}{ Model 3} \\
\hline & OR $(95 \% \mathrm{Cl})$ & $P$ & OR $(95 \% \mathrm{Cl})$ & $P$ & OR $(95 \% \mathrm{Cl})$ & $P$ \\
\hline Age (years) & $1.002(0.987-1.018)$ & 0.771 & $1.011(0.993-1.029)$ & 0.226 & $0.990(0.970-1.009)$ & 0.303 \\
\hline Gender (M/F) & $1.102(0.770-1.577)$ & 0.594 & $1.555(1.043-2.320)$ & 0.030 & $1.714(1.105-2.658)$ & 0.016 \\
\hline BMI $\left(\mathrm{kg} / \mathrm{m}^{2}\right)$ & 1.039 (0.985-1.095) & 0.157 & $0.997(0.942-1.056)$ & 0.926 & $0.979(0.919-1.042)$ & 0.506 \\
\hline SBP $(\mathrm{mmHg})$ & - & - & - & - & $1.066(1.047-1.086)$ & $<0.001$ \\
\hline $\mathrm{DBP}(\mathrm{mmHg})$ & - & - & - & - & $0.978(0.951-1.006)$ & 0.126 \\
\hline $\mathrm{TG}(\mathrm{mmol} / \mathrm{L})$ & - & - & $0.941(0.763-1.162)$ & 0.573 & $0.957(0.772-1.186)$ & 0.690 \\
\hline $\mathrm{TC}(\mathrm{mmol} / \mathrm{L})$ & - & - & $3.247(1.310-8.050)$ & 0.011 & $2.943(1.235-7.012)$ & 0.015 \\
\hline $\mathrm{HDL}(\mathrm{mmol} / \mathrm{L})$ & - & - & $0.025(0.008-0.078)$ & $<0.001$ & $0.032(0.010-0.099)$ & $<0.001$ \\
\hline $\mathrm{LDL}(\mathrm{mmol} / \mathrm{L})$ & - & - & $0.534(0.211-1.351)$ & 0.185 & $0.534(0.222-1.286)$ & 0.162 \\
\hline c.1012C>G polymorphism & $0.704(0.551-0.899)$ & 0.005 & $0.768(0.589-0.989)$ & 0.042 & $0.773(0.578-1.032)$ & 0.081 \\
\hline
\end{tabular}

Italic values indicate significance of $P$ value $(P<0.05)$

Model 1: adjust for age, gender, and BMI

Model 2: adjust for age, gender, BMI, and lipid

Model 3: adjust for age, gender, BMI, lipid, and blood pressure 
Table 4 Comparison of characteristics of different genotypes of c.1012C>G polymorphism of NUCB2 gene in T2DM subjects

\begin{tabular}{lllll}
\hline $\begin{array}{l}\text { Character- } \\
\text { istics }\end{array}$ & CC $(\mathbf{n}=\mathbf{1 6 9})$ & CG $(\mathbf{n}=\mathbf{1 7 3})$ & $\mathbf{G G}(\mathbf{n}=\mathbf{5 4})$ & $\boldsymbol{P}$ \\
\hline Age (years) & $57.01 \pm 10.69$ & $56.18 \pm 12.81$ & $56.41 \pm 12.02$ & 0.810 \\
Gender (M/F) & $92 / 77$ & $88 / 85$ & $30 / 24$ & 0.742 \\
BMl (kg/m $)$ & $25.31 \pm 3.76$ & $24.97 \pm 3.68$ & $23.81 \pm 3.16^{a, b}$ & 0.032 \\
SBP $(\mathrm{mmHg})$ & $138.61 \pm 21.99$ & $139.10 \pm 22.55$ & $141.20 \pm 23.95$ & 0.761 \\
DBP $(\mathrm{mmHg})$ & $83.43 \pm 14.05$ & $84.51 \pm 12.27$ & $85.37 \pm 11.85$ & 0.570 \\
FPG (mmol/L) & $7.88 \pm 1.67$ & $7.78 \pm 1.81$ & $7.12 \pm 1.36^{a, b}$ & 0.016 \\
TG (mmol/L) & $1.91 \pm 1.40$ & $1.81 \pm 1.43$ & $1.96 \pm 1.37$ & 0.730 \\
TC (mmol/L) & $5.24 \pm 1.22$ & $5.16 \pm 1.14$ & $5.18 \pm 0.88$ & 0.792 \\
HDL (mmol/L) & $1.25 \pm 0.30$ & $1.30 \pm 0.35$ & $1.25 \pm 0.29$ & 0.348 \\
LDL (mmol/L) & $3.41 \pm 0.98$ & $3.37 \pm 1.01$ & $3.37 \pm 0.73$ & 0.915 \\
\hline
\end{tabular}

Italic values indicate significance of $P$ value $(P<0.05)$

a Significant versus MetS patients with $C \mathrm{C}$ genotype

${ }^{\text {b }}$ Significant versus MetS patients with CG genotype

significantly decreased in the hypothalamus of Tsumura Suzuki obese diabetes mice compared with the control mice [13]. In addition, plasma nesfatin-1 concentrations were significantly decreased in T2DM patients compared with healthy controls $[5,6]$. However, another study demonstrated increased plasma nesfatin-1 in patients with newly diagnosed T2DM [14]. The explanation for these conflicting data is unclear but may be attributable to differences in disease advancement, populations, or assays applied.

Recently, the c. $1012 \mathrm{C}>\mathrm{G}$ polymorphism of NUCB2 gene was found to be correlated with obesity $[7,8]$. Obesity is a risk factor of developing T2DM. Therefore, we hypothesized that the c.1012C $>$ G polymorphism of NUCB2 gene may be also correlated with the risk of developing T2DM. The present study indicated that the c.1012C $>$ G polymorphism of NUCB2 gene was associated with a decreased risk of developing T2DM. NUCB2 is considered to be a susceptibility gene for T2DM. The c.1012C $>$ G polymorphism of NUCB2 could be utilized as a genetic marker to assess the risk of developing T2DM. However, when considering the blood pressure as the adjusting factor, the c.1012C $>$ G polymorphism of NUCB2 was not correlated with the risk of developing T2DM. Traditionally, blood pressure is not a potential risk factor for T2DM. Therefore, we think blood pressure is confounding factor and should be excluded. The c. $1012 \mathrm{C}>\mathrm{G}$ polymorphism of NUCB2 gene was demonstrated to be associated with the risk of developing T2DM.

The potential limitations of these data merit consideration. First, as our study was conducted in a sample of Chinese Han population, extrapolation of the data to other ethnic groups should be done with great caution. Second, the study population was relatively small. Therefore, our results require further investigation in a larger sample size.

\section{Conclusions}

In conclusion, this study revealed that the c.1012C $>\mathrm{G}$ polymorphism of NUCB2 gene was associated with the risk of developing T2DM. The c.1012C $>\mathrm{G}$ polymorphism of NUCB2 gene is suggested to be an independent genetic marker of the risk of T2DM.

\section{Abbreviations \\ T2DM: type 2 diabetes mellitus; NUCB2: nucleobindin 2; FPG: fasting plasma glucose; $\mathrm{P}_{2 \mathrm{~h}}$ PG: 2-h postprandial plasma glucose; SBP: systolic blood pressure; DBP: diastolic blood pressure; TG: triglycerides; TC: total cholesterol; HDL-C: high-density lipoprotein cholesterol; LDL-C: low-density lipoprotein choles- terol; BMI: body mass index; PCR: polymerase chain reaction; SD: standard deviation.}

\section{Authors' contributions}

WH researched literature and conceived the study. CW and YW were involved in protocol development, gaining ethical approval, patient recruitment and data analysis. All authors reviewed and edited the manuscript. All authors read and approved the final manuscript.

\section{Author details}

${ }^{1}$ Department of Clinical Laboratory, Shanxi Provincial People's Hospital, Taiyuan, China. ${ }^{2}$ Department of Endocrinology, Tianjin People's Hospital, Tianjin, China. ${ }^{3}$ Department of Endocrinology, Qilu Hospital of Shandong University (Qingdao), 758 Hefei Road, Shibei District, Qingdao 266035, Shandong, China.

\section{Acknowledgements}

None.

\section{Competing interests}

The authors declare that they have no competing interests.

\section{Availability of data and materials}

All data and materials are available.

Consent for publication

All authors consent for publication.

\section{Ethics approval and consent to participate}

The study was approved by the Hospital ethics board and all patients provided written informed consent.

\section{Publisher's Note}

Springer Nature remains neutral with regard to jurisdictional claims in published maps and institutional affiliations.

Received: 27 May 2016 Accepted: 9 May 2017

Published online: 19 May 2017

\section{References}

1. Guillausseau PJ, Meas T, Virally M, Laloi-Michelin M, Médeau V, Kevorkian JP. Abnormalities in insulin secretion in type 2 diabetes mellitus. Diabetes Metab. 2008;34(Suppl 2):S43-8.

2. Collaboration Emerging Risk Factors, Seshasai SR, Kaptoge S, et al. Diabetes mellitus, fasting glucose, and risk of cause-specific death. N Engl J Med. 2011;364:829-41.

3. McCarthy MI, Froguel P. Genetic approaches to the molecular understanding of type 2 diabetes. Am J Physiol Endocrinol Metab. 2002;283:E217-25. 
4. Nakata M, Yada T. Role of NUCB2/nesfatin-1 in glucose control: diverse functions in islets, adipocytes and brain. Curr Pharm Des. 2013;19:6960-5.

5. Li QC, Wang HY, Chen X, Guan HZ, Jiang ZY. Fasting plasma levels of nesfatin- 1 in patients with type 1 and type 2 diabetes mellitus and the nutrient-related fluctuation of nesfatin-1 level in normal humans. Regul Pept. 2010;159:72-7.

6. Liu F, Yang Q, Gao N, Liu F, Chen S. Decreased plasma nesfatin-1 level is related to the thyroid dysfunction in patients with type 2 diabetes mellitus. J Diabetes Res. 2014;2014:128014.

7. Zegers D, Beckers S, Mertens IL, Van Gaal LF, Van Hul W. Association between polymorphisms of the Nesfatin gene, NUCB2, and obesity in men. Mol Genet Metab. 2011;103:282-6.

8. Chen YY, Chan RM, Tan KM, et al. The association of a nucleobindin 2 gene (NUCB2) variant with childhood adiposity. Gene. 2013;516:48-52.

9. Riva M, Nitert MD, Voss U, et al. Nesfatin-1 stimulates glucagon and insulin secretion and beta cell NUCB2 is reduced in human type 2 diabetic subjects. Cell Tissue Res. 2011;346:393-405
10. Gonzalez R, Reingold BK, Gao X, Gaidhu MP, Tsushima RG, Unniappan S. Nesfatin-1 exerts a direct, glucose-dependent insulinotropic action on mouse islet $\beta$ - and MIN6 cells. J Endocrinol. 2011;208:R9-16.

11. Yang $M$, Zhang Z, Wang $C$, et al. Nesfatin-1 action in the brain increases insulin sensitivity through Akt/AMPK/TORC2 pathway in diet-induced insulin resistance. Diabetes. 2012;61:1959-68.

12. Wu $D$, Yang $M, C$ hen $Y$, et al. Hypothalamic nesfatin-1/NUCB2 knockdown augments hepatic gluconeogenesis that is correlated with inhibition of mTOR-STAT3 signaling pathway in rats. Diabetes. 2014;63:1234-47.

13. Miyata S, Yamada N, Kawada T. Possible involvement of hypothalamic nucleobindin-2 in hyperphagic feeding in Tsumura Suzuki obese diabetesmice. Biol Pharm Bull. 2012;35:1784-93.

14. Zhang Z, Li L, Yang M, Liu H, Boden G, Yang G. Increased plasma levels of nesfatin-1 in patients with newly diagnosed type 2 diabetes mellitus. Exp Clin Endocrinol Diabetes. 2012;120:91-5.

\section{Submit your next manuscript to BioMed Central and we will help you at every step:}

- We accept pre-submission inquiries

- Our selector tool helps you to find the most relevant journal

- We provide round the clock customer support

- Convenient online submission

- Thorough peer review

- Inclusion in PubMed and all major indexing services

- Maximum visibility for your research

Submit your manuscript at www.biomedcentral.com/submit 